\title{
An efficient numerical method and new analytical model for the prediction of the five parameters of photovoltaic generators under non-STC conditions
}

\author{
Kawtar Tifidat, Noureddine Maouhoub*, and Abdelaaziz Benahmida \\ Laboratory of Electronics, Signal Processing and Physical Modeling, Department of Physics, Faculty of Sciences, Ibn Zohr University, \\ B.P 8106, Agadir, Morocco
}

\begin{abstract}
In this work, the single-diode model is used to model the PV generator. Then, a numerical method is introduced to extract its five parameters using just the values of the key-points. To this end, we apply the $\mathrm{I}-\mathrm{V}$ characteristic on the three remarkable points to get three equations with five unknowns. To complete the necessary system of five equations, the two other remaining equations are extracted as follow; the first, from the derivative of the equation linking the generator's current to its voltage. Second, an expression linking the fill-factor to the four parameters: Is, Rp, Rs and $n$ is used as the fifth equation. This method is serves to extract the five parameters using five equations, without using any approximation. The accuracy of this approach is evaluated using experimental data for a solar cell, and extracted data from datasheet for a PV panel. Then, using some statistical indicators, this method has shown a good accuracy. Moreover, to get the values of the five parameters for non-standard conditions, and predict the I-V curves and the maximum power, a new analytical model of open-circuit voltage as a function of the module temperature and irradiance is presented as well in this paper.
\end{abstract}

\section{Introduction}

Nowadays, the technological development, which is growing more and more, involves an increasing consumption of energy. Even if it entails air and water pollution, thing which means many environmental and health problems, fossil fuels remain the most used sources to meet these needs. Since the excessive consumption implies the reduction of these natural resources as well, a switch to renewable energies seems to be necessary. Solar is one of the renewable sources on which many countries rely as an alternative. Morocco is one of the major countries that have invested in the production of this type of energy. Initially, a project with a total production capacity of $2000 \mathrm{MW}$ was launched in 2009. To this end, the city of Ouarzazate was chosen and this was due to its high level of irradiation [1].

The use of photovoltaic energy production systems makes of the modelling of these systems an important need. Thus, the physical effects within the system can be modelled, and its performance and behaviour under different levels of solar radiation and temperature can be predicted. Given its simplicity of use and its efficacy, the one-diode model with five parameters $\left(I_{s}, R_{p}, R_{s}, I_{p h}\right.$ and $\mathrm{n}$ ) is the most chosen by the authors.

In order to extract the parameters of a PV generator, several methods have been introduced in the literature, thing that allows the prediction of the maximum power point as well. In this regard, and until now, all the introduced approaches can be classified based on three types of extraction. First, we have the methods based on the available information about the key-points (open circuit voltage, short circuit current and maximum power conditions) on the $\mathrm{PV}$ generator's datasheet $[2,3$, 4]. Second, we find numerical approaches that rely on minimizing the error between theoretical and experimental I-V characteristics. This kind of extraction generally does not need any kind of information about the remarkable points from the datasheet, they are based just on the fitting procedures $[5,6]$. Third, we have the evolutionary methods, which use the meta-heuristic algorithms based on the different natural phenomena [7].

In order to extract numerically the single diode five parameters, Kumar et al [2] use a system of five nonlinear equations based on the remarkable points. And as initial guesses for this system, they use a set of five analytical equations. This method relies on many approximations to obtain the five non-linear equations.

To extract the five parameters, the introduced method in this work is based on the numerical resolution of a system of five equations. The first three equations are extracted from the application of the characteristic equation on the key-points. The two last equations are extracted respectively as follow: we get the first using the derivative of the equation linking the generated current to the voltage applied to the maximum power

* Corresponding author: n.maouhoub@uiz.ac.ma 
point, and we get the last using the expression linking the fill factor to four parameters $\left(I_{s}, R_{p}, R_{s}\right.$ and $\left.n\right)$. To ensure the convergence of the extracted values towards the exact solutions, a good initialization of the numerical resolution of the five non-linear equations system is necessary. To this end, a set of five analytical equations extracted based on approximations is used as initial guesses. Furthermore, to predict the five parameters and the I-V curves for non-standard test conditions, a new analytical expression of open-circuit voltage as function of the module's temperature and solar irradiation level is proposed.

The organization of this work is as follows: in the second section, the one-diode equivalent circuit model of the PV generator is introduced. In the third part, we detail the theory on which the current method is based on to extract the five parameters. In the fourth part, the accuracy of the method for the RTC solar cell and the SQ80 PV panel is performed, and the new analytical contribution to the prediction of the I-V characteristic for non-standard test conditions is introduced as well. Finally, the paper ends with a conclusion.

\section{Single diode equivalent circuit model}

In this work, we rely on the single diode model to characterize the photovoltaic generators. The equivalent circuit below corresponds to this model, it consists of a diode that has a reverse saturation current $I_{s}$ and an ideality factor $n$, a generator of the photo-current $\mathrm{I}_{\mathrm{ph}}$, the series parasitic resistance $R_{s}$ and the shunt parasitic resistance $R_{p}$. The set of all these circuit characteristics constitutes the five parameters of the model.

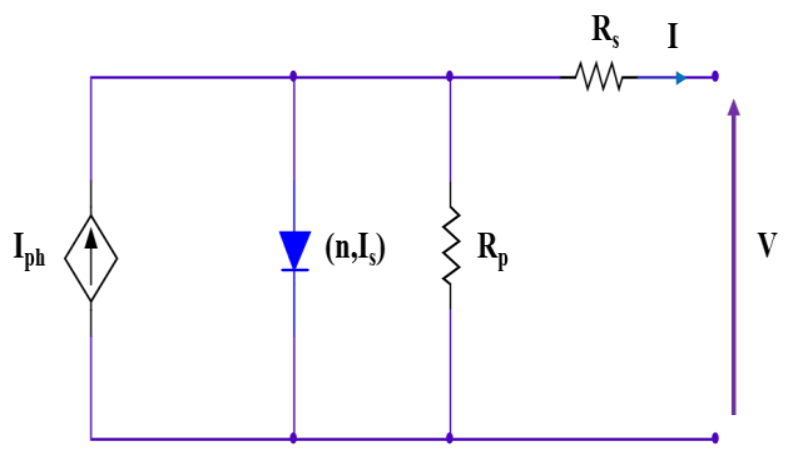

Fig. 1. Equivalent electrical circuit for single diode model.

The characteristic equation linking the current to the voltage is given by:

$$
I=I_{\mathrm{ph}}-I_{\mathrm{d}}-I_{\mathrm{p}}
$$
follows:

Where $I_{d}$ is the diode current and it is given as

$$
I_{\mathrm{d}}=I_{\mathrm{s}}\left(\exp \left(\frac{V+I R_{\mathrm{s}}}{n \mathrm{~N}_{\mathrm{s}} V_{\text {th }}}\right)-1\right)
$$

$\mathrm{V}_{\text {th }}$ is the thermal voltage defined by: $V_{\mathrm{th}}=\frac{\mathrm{K}_{\mathrm{B}} T}{\mathrm{q}}$
Where $\mathrm{k}_{\mathrm{B}}$ is the Boltzmann's constant equal to $1.38 .10^{-23} \mathrm{~J} / \mathrm{K}, \mathrm{q}$ is the electron charge equal to 1.602 $.10^{-19} \mathrm{C}$.

$\mathrm{N}_{\mathrm{s}}$ is the number of solar cells connected in series.

Developing (1), the characteristic equation of a PV generator can be written as:

$$
I=I_{\mathrm{ph}}-I_{\mathrm{s}}\left(\exp \left(\frac{V+I R_{\mathrm{s}}}{n \mathrm{~N}_{\mathrm{s}} V_{\mathrm{th}}}\right)-1\right)-\frac{V+I R_{\mathrm{s}}}{R_{\mathrm{p}}}
$$

With the help of the lambert W function, the implicit expression in equation (3) can be solved analytically and written as [8]:

$$
\begin{aligned}
& I=\frac{I_{\mathrm{s}}+I_{\mathrm{ph}}}{1+R_{\mathrm{s}} G_{\mathrm{p}}}-\frac{G_{\mathrm{p}}}{1+R_{\mathrm{s}} G_{\mathrm{p}}} V-\frac{n \mathrm{~N}_{\mathrm{s}} V_{\mathrm{th}}}{R_{\mathrm{s}}} \times \\
& \mathrm{W}\left(\frac{I_{\mathrm{s}} R_{\mathrm{s}}}{n \mathrm{~N}_{\mathrm{s}} V_{\mathrm{th}}\left(1+R_{\mathrm{s}} G_{\mathrm{p}}\right)} \exp \left(\frac{V+R_{\mathrm{s}}\left(I_{\mathrm{s}}+I_{\mathrm{ph}}\right)}{n \mathrm{~N}_{\mathrm{s}} V_{\mathrm{th}}\left(1+R_{\mathrm{s}} G_{\mathrm{p}}\right)}\right)\right)
\end{aligned}
$$

Where $G_{\mathrm{p}}=\frac{1}{R_{\mathrm{p}}}$.

\section{Numerical method}

\subsection{System of five equations}

The equation (3) is calculated for the three remarkable points of the I-V curve, to get the following expressions:

- Short circuit current $\left(I=I_{\mathrm{sc}}, V=0\right)$

$$
I_{\mathrm{sc}}-I_{\mathrm{ph}}+I_{\mathrm{s}}\left(\exp \left(\frac{I_{\mathrm{sc}} R_{\mathrm{s}}}{n \mathrm{~N}_{\mathrm{s}} V_{\mathrm{th}}}\right)-1\right)+\frac{I_{\mathrm{sc}} R_{\mathrm{s}}}{R_{\mathrm{p}}}=0
$$

- Maximum power point $\left(I=I_{\mathrm{mp}}, V=V_{\mathrm{mp}}\right)$

$$
\begin{aligned}
& I_{\mathrm{mp}}-I_{\mathrm{ph}}+I_{\mathrm{s}}\left(\exp \left(\frac{V_{\mathrm{mp}}+I_{\mathrm{mp}} R_{\mathrm{s}}}{n \mathrm{~N}_{\mathrm{s}} V_{\mathrm{th}}}\right)-1\right) \\
& +\frac{V_{\mathrm{mp}}+I_{\mathrm{mp}} R_{\mathrm{s}}}{R_{\mathrm{p}}}=0
\end{aligned}
$$

- Open circuit voltage $\left(I=0, V=V_{\text {oc }}\right)$

$$
I_{\mathrm{ph}}-I_{\mathrm{s}}\left(\exp \left(\frac{V_{\mathrm{oc}}}{n \mathrm{~N}_{\mathrm{s}} V_{\mathrm{th}}}\right)-1\right)-\frac{V_{\mathrm{oc}}}{R_{\mathrm{p}}}=0
$$

The fourth equation can be extracted by calculating the derivative of the current I with respect to the voltage $\mathrm{V}$. Then, the expression is applied for the maximum power point, and we get the following expression: 


$$
\begin{aligned}
& \left.\frac{\mathrm{d} I}{\mathrm{~d} V}\right|_{\left(P=P_{\mathrm{mp}}\right)}=-\frac{I_{\mathrm{s}}}{n \mathrm{~N}_{\mathrm{s}} V_{\mathrm{th}}}\left(1+\left.R_{\mathrm{s}} \frac{\mathrm{d} I}{\mathrm{~d} V}\right|_{\left(P=P_{\mathrm{mp}}\right)}\right) \\
& \times \exp \left(\frac{V_{\mathrm{mp}}+I_{\mathrm{mp}} R_{\mathrm{s}}}{n \mathrm{~N}_{\mathrm{s}} V_{\mathrm{th}}}\right)-\frac{1}{R_{\mathrm{p}}}\left(1+\left.R_{\mathrm{s}} \frac{\mathrm{d} I}{\mathrm{~d} V}\right|_{\left(P=P_{\mathrm{mp}}\right)}\right)
\end{aligned}
$$

For the maximum power point, we have:

$$
\left.\frac{\mathrm{d} I}{\mathrm{~d} V}\right|_{\left(P=P_{\mathrm{mp}}\right)}=-\frac{I_{\mathrm{mp}}}{V_{\mathrm{mp}}}
$$

From (8) and (9), we get the fourth equation as:

$$
\begin{aligned}
& \frac{I_{\mathrm{mp}}}{V_{\mathrm{mp}}}-\left(1-R_{\mathrm{s}} \frac{I_{\mathrm{mp}}}{V_{\mathrm{mp}}}\right) \\
& \times\left(\frac{I_{\mathrm{s}}}{n \mathrm{~N}_{\mathrm{s}} V_{\mathrm{th}}} \exp \left(\frac{V_{\mathrm{mp}}+I_{\mathrm{mp}} R_{\mathrm{s}}}{n \mathrm{~N}_{\mathrm{s}} V_{\mathrm{th}}}\right)-\frac{1}{R_{\mathrm{p}}}\right)=0
\end{aligned}
$$

The expression linking the fill-factor to the four parameters $\left(I_{s}, R_{p}, R_{s}\right.$ and $\left.n\right)$ is chosen as the last equation of the system of the five non-linear equations to extract the five parameters [9].

$F F-\frac{I_{\mathrm{mp}}^{2}}{V_{\mathrm{oc}} I_{\mathrm{sc}}}\left(R_{\mathrm{s}}+\frac{R_{\mathrm{p}}}{\frac{I_{\mathrm{s}} R_{\mathrm{p}}}{n \mathrm{~N}_{\mathrm{s}} V_{\text {th }}} \exp \left(\frac{V_{\mathrm{mp}}+I_{\mathrm{mp}} R_{\mathrm{s}}}{n \mathrm{~N}_{\mathrm{s}} V_{\text {th }}}\right)-1}\right)=0$

To extract the five parameters $I_{s}, n, I_{p h}, R_{s}$ and $R_{p}$. we solve numerically the system of non-linear equations (5), (6), (7), (9) and (10) using the MATLAB command "fsolve".

\subsection{Initial values}

The numerical resolution of the system of non-linear equations obtained in the previous section needs a good initialization, which will ensure the convergence of the system to the solutions. To this end, the following analytical equations based on some approximations will be used to get the initial values [2]:

$$
\begin{aligned}
& R_{\mathrm{s}}=\frac{V_{\mathrm{mp}}}{I_{\mathrm{mp}}}-\frac{2 V_{\mathrm{mp}}-V_{\mathrm{oc}}}{\left(I_{\mathrm{sc}}-I_{\mathrm{mp}}\right)\left(\ln \left(1-\frac{I_{\mathrm{mp}}}{I_{\mathrm{sc}}}\right)+\frac{I_{\mathrm{mp}}}{I_{\mathrm{sc}}-I_{\mathrm{mp}}}\right)} \\
& n=\frac{2 V_{\mathrm{mp}}-V_{\mathrm{oc}}}{\mathrm{N}_{\mathrm{s}} V_{\mathrm{th}}\left(\ln \left(1-\frac{I_{\mathrm{mp}}}{I_{\mathrm{sc}}}\right)+\frac{I_{\mathrm{mp}}}{I_{\mathrm{sc}}-I_{\mathrm{mp}}}\right)} \\
& \left\{R_{\mathrm{p}}=\sqrt{\frac{R_{\mathrm{s}}}{\frac{I_{\mathrm{s}}}{\mathrm{N}_{\mathrm{s}} V_{\mathrm{th}}} \exp \left(\frac{I_{\mathrm{sc}} R_{\mathrm{s}}}{n \mathrm{~N}_{\mathrm{s}} V_{\mathrm{th}}}\right)}}\right. \\
& I_{\mathrm{ph}}=I_{\mathrm{s}}\left(\exp \left(\frac{V_{\mathrm{oc}}}{n \mathrm{~N}_{\mathrm{s}} V_{\mathrm{th}}}\right)-1\right)+\frac{V_{\mathrm{oc}}}{R_{\mathrm{p}}} \\
& I_{\mathrm{s}}=\frac{I_{\mathrm{sc}}\left(R_{\mathrm{p}}+R_{\mathrm{s}}\right)-V_{\mathrm{oc}}}{R_{\mathrm{p}}\left(\exp \left(\frac{V_{\mathrm{oc}}}{n \mathrm{~N}_{\mathrm{s}} V_{\mathrm{th}}}\right)-\exp \left(\frac{I_{\mathrm{sc}} R_{\mathrm{s}}}{n \mathrm{~N}_{\mathrm{s}} V_{\mathrm{th}}}\right)\right)}
\end{aligned}
$$

\section{Results and discussion}

With the aim of validating the efficacy of the current approach, we chose two cases of measured data to compare with the calculated characteristics. The first is the commercial silicon solar cell (RTC France) at $33^{\circ} \mathrm{C}$, and $1000 \mathrm{~W} / \mathrm{m}^{2}$ [6]. The second is the mono-crystalline PV panel (Shell SQ80) with 36 solar cells connected in series, working under standard test conditions STC $\left(\mathrm{T}=25^{\circ} \mathrm{C}\right.$ and $\left.\mathrm{G}=1000 \mathrm{~W} / \mathrm{m}^{2}\right)[10]$.

We first extract the five parameters of the panel under STC. Subsequently, we predict its I-V and P-V characteristics for non-standard conditions.

Table 1 shows the values of the key-points (the short circuit current, maximum power points and the open circuit voltage) extracted from the experimental I-V characteristic.

Table 1. Extracted specific parameters from measured I-V characteristic for the RTC solar cell at $\mathrm{G}=1000 \mathrm{~W} / \mathrm{m}^{2}$ and $\mathrm{T}=33^{\circ} \mathrm{C}$.

\begin{tabular}{|c|c|}
\hline Parameter & Value \\
\hline $\mathrm{I}_{\mathrm{sc}}(\mathrm{A})$ & 0.7605 \\
\hline $\mathrm{I}_{\mathrm{mp}}(\mathrm{A})$ & 0.68107 \\
\hline $\mathrm{V}_{\mathrm{mp}}(\mathrm{V})$ & 0.4511 \\
\hline $\mathrm{V}_{\mathrm{oc}}(\mathrm{V})$ & 0.5727 \\
\hline $\mathrm{P}(\mathrm{W})$ & 0.307 \\
\hline
\end{tabular}

Table 2 contains the values of the key-points (the short circuit current, maximum power points and the open circuit voltage) available in the datasheet, as well as the extracted values from the measured I-V characteristic. As it can be seen, the extracted values and the values available in datasheet are a bit different, thing which might highly affect the values of the statistical 
indicators relating to the method, and the accuracy of the extraction for outdoor conditions.

Table 2. Specific parameters available in datasheet and extracted from measured I-V characteristic for the PV panel Shell SQ80 at standard test conditions.

\begin{tabular}{|c|c|c|}
\hline Parameter & Datasheet value & $\begin{array}{c}\text { Measured } \\
\text { Value }\end{array}$ \\
\hline $\mathrm{I}_{\mathrm{sc}}(\mathrm{A})$ & 4.85 & 4.8384 \\
\hline $\mathrm{I}_{\mathrm{mp}}(\mathrm{A})$ & 4.58 & 4.52 \\
\hline $\mathrm{V}_{\mathrm{mp}}(\mathrm{V})$ & 17.5 & 17.38 \\
\hline $\mathrm{V}_{\mathrm{oc}}(\mathrm{V})$ & 21.8 & 21.8003 \\
\hline $\mathrm{P}(\mathrm{W})$ & 80 & 78.602 \\
\hline
\end{tabular}

In order to provide the accuracy of this method, several statistical indicators can be used. In this work, we chose the Root Mean Square Error (RMSE) and the Normalized Root Mean Square Error (NRMSE) as well as the absolute error (AE) as indicators:

$$
\begin{aligned}
R M S E & =\left[\frac{1}{\mathrm{~N}} \sum_{\mathrm{i}=1}^{\mathrm{N}}\left(I_{\mathrm{i}, \text { Measured }}-I_{\mathrm{i}, \text { calculated }}\right)^{2}\right]^{\frac{1}{2}} \\
N R M S E & =\frac{\sqrt{\frac{1}{\mathrm{~N}} \sum_{\mathrm{i}=1}^{\mathrm{N}}\left(I_{\mathrm{i}, \text { Measured }}-I_{\mathrm{i}, \text { calculated }}\right)^{2}}}{\frac{1}{\mathrm{~N}} \sum_{\mathrm{i}=1}^{\mathrm{N}} I_{\mathrm{i}, \text { Measured }}} \\
A E & =\left|X_{\mathrm{i}, \text { Measured }}-X_{\mathrm{i}, \text { Calculated }}\right|
\end{aligned}
$$

Where $\mathrm{N}$ is the number of measured data points. $\mathrm{X}$ stands for current I or power $\mathrm{P}$.

\subsection{Results for RTC solar cell}

Table 3 regroups the extracted parameters for the RTC solar cell using the current method, and the parameters obtained using Kumar's method. As it appears clearly from the table, the current approach corresponds to the lowest values of NRMSE and RMSE.

Table 3. Extracted parameters for the RTC solar cell working under $\left(\mathrm{G}=1000 \mathrm{~W} / \mathrm{m}^{2}\right.$ and $\left.\mathrm{T}=33^{\circ} \mathrm{C}\right)$.

\begin{tabular}{|c|c|c|}
\hline & Kumar [2] & $\begin{array}{c}\text { Proposed } \\
\text { Method }\end{array}$ \\
\hline $\mathbf{I}_{\mathbf{p h}} \mathbf{( A )}$ & 0.760971 & 0.760790 \\
\hline $\mathbf{I}_{\mathbf{s}} \mathbf{( A )}$ & $1.0794 \times 10^{-6}$ & $2.876403 \times 10^{-6}$ \\
\hline $\mathbf{R}_{\mathbf{s}}(\mathbf{\Omega})$ & 0.012199 & 0.019149 \\
\hline $\mathbf{R}_{\mathbf{s h}}(\mathbf{\Omega})$ & 19.69947 & 50.2495 \\
\hline $\mathbf{n}$ & 1.616567 & 1.740557 \\
\hline RMSE & 0.023182 & 0.008590 \\
\hline NRMSE (\%) & 4.203018 & 1.55742 \\
\hline
\end{tabular}

Figures 2 and 3 show respectively the experimental $\mathrm{I}-\mathrm{V}$ and $\mathrm{P}-\mathrm{V}$ characteristics, represented by the black markers and the predicted curves using the new approach and Kumar's method, represented using the lines. The theoretical curve obtained using the present method corresponds exactly to the experimental data points.

Figure 4 shows the absolute errors relating to both methods. It is clear that for the great majority of the voltage's values, the current method shows the lowest values of the absolute error between the experimental and theoretical curves.

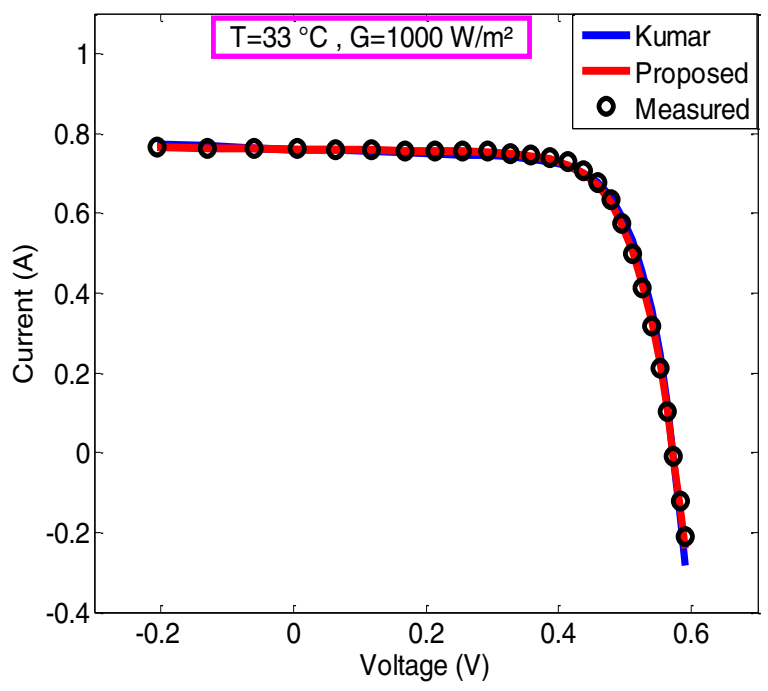

Fig. 2. Predicted I-V curves using the two methods and measured data for the RTC solar cell.

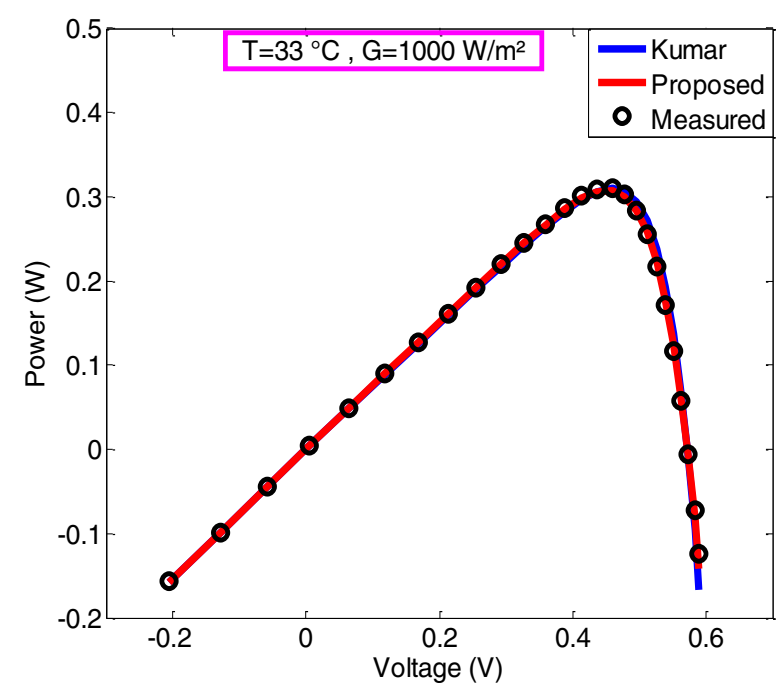

Fig. 3. Predicted P-V curves using the two methods and measured data for the RTC solar cell. 


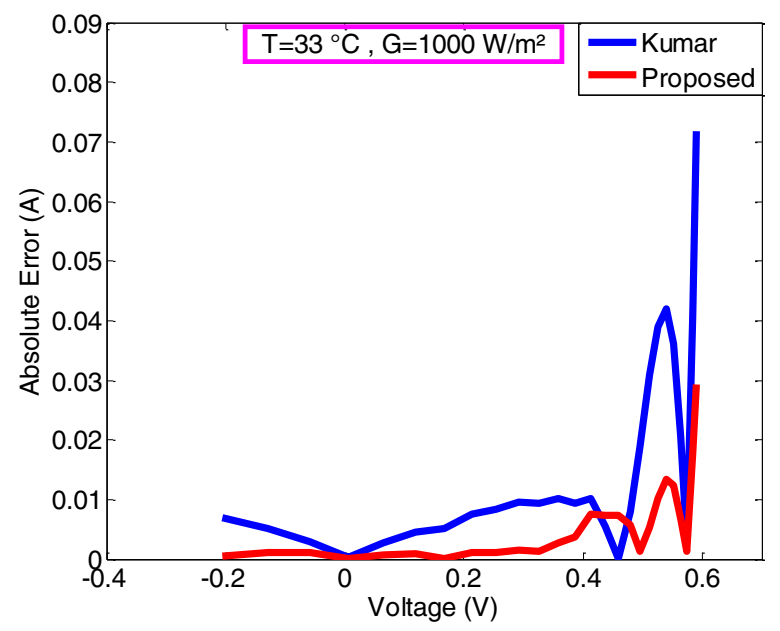

Fig. 4. Absolute errors of the two methods for the RTC solar cell.

\subsection{Results for shell SQ80 PV model}

\subsubsection{Results at standard test conditions (STC)}

Table 4 regroups the extracted parameters, the values of RMSE, and the values of NRMSE obtained for the mono-crystalline PV panel Shell SQ80 using the proposed method and compared to two other methods proposed in the literature. According to this table, the current approach shows the best accuracy by giving the lowest value of the statistical errors RMSE and NRMSE.

Table 4. Extracted parameters for the PV model Shell SQ80.

\begin{tabular}{|c|c|c|c|}
\hline & Kumar [2] & $\begin{array}{c}\text { Analytical } \\
{[2]}\end{array}$ & $\begin{array}{c}\text { Proposed } \\
\text { Method }\end{array}$ \\
\hline $\mathbf{I}_{\mathbf{p h}}(\mathbf{A})$ & 4.8501 & 4.8499 & 4.8510 \\
\hline $\mathbf{I}_{\mathbf{s}}(\mathbf{A})$ & $\begin{array}{c}3.4182 \\
\times 10^{-10}\end{array}$ & $\begin{array}{c}3.8959 \\
\times 10^{-10}\end{array}$ & $2.0591 \times 10^{-8}$ \\
\hline $\mathbf{R}_{\mathbf{s}}(\mathbf{\Omega})$ & 0.3498 & 0.3474 & 0.2969 \\
\hline $\mathbf{R}_{\mathbf{s h}}(\mathbf{\Omega})$ & 12441.04 & 11775 & 1436.83 \\
\hline $\mathbf{n}$ & 1.0082 & 1.0139 & 1.2227 \\
\hline $\mathbf{R M S E}$ & 0.08217 & 0.08219 & 0.04932 \\
\hline $\begin{array}{c}\mathbf{N R M S E} \\
\mathbf{( \% )}\end{array}$ & 2.6642 & 2.6647 & 1.5819 \\
\hline
\end{tabular}

Figure 5 and figure 6 present respectively the I-V and $\mathrm{P}-\mathrm{V}$ characteristics extracted using the three methods (presented using the lines) and the one measured (presented using the black markers). As reported in the figures, the predicted I-V and P-V characteristics using this approach pass on all measured data points.

Figure 7 shows the absolute errors obtained using the three methods. As it clearly appears, the current technique guarantees the best prediction of the maximum power point.

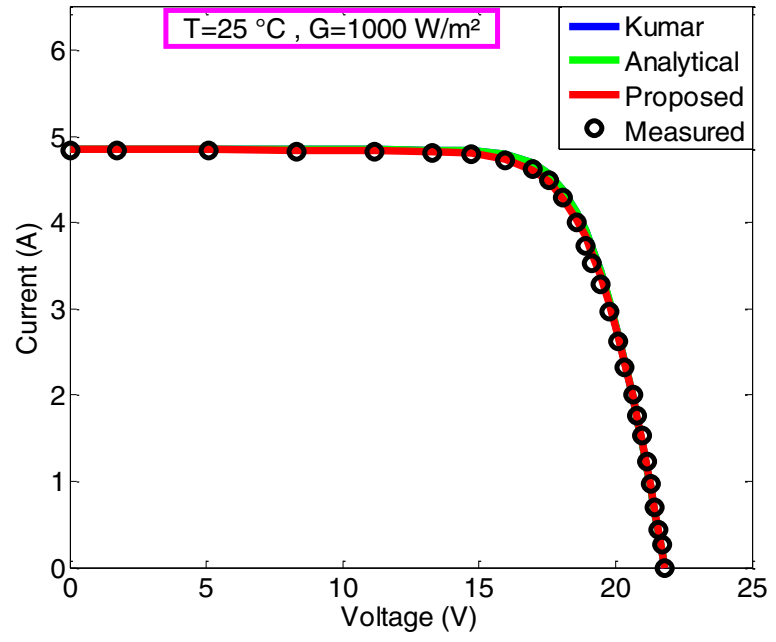

Fig. 5. Predicted I-V curves using the three methods and measured data, for the PV module Shell SQ80 under STC conditions.

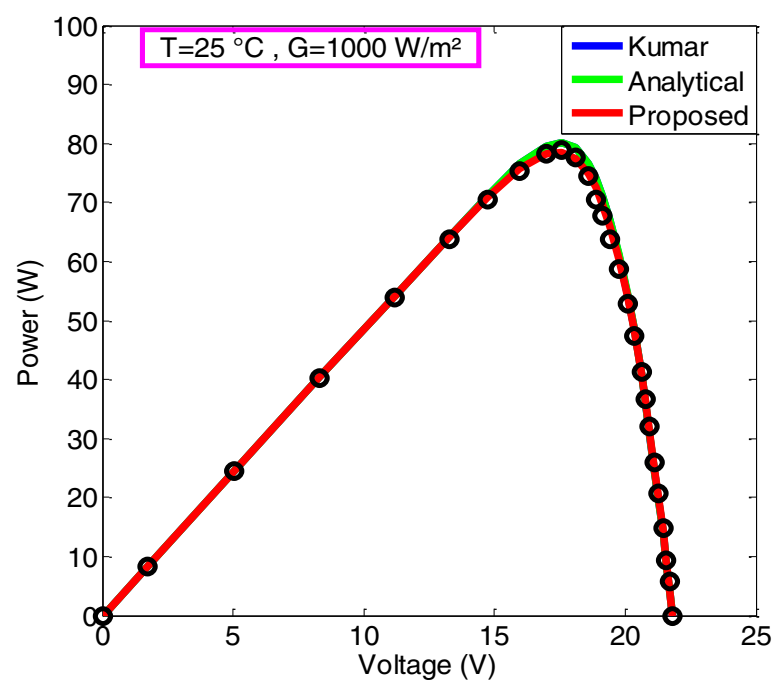

Fig. 6. Predicted P-V curves using the three methods and measured data for the PV module Shell SQ80 under STC conditions.

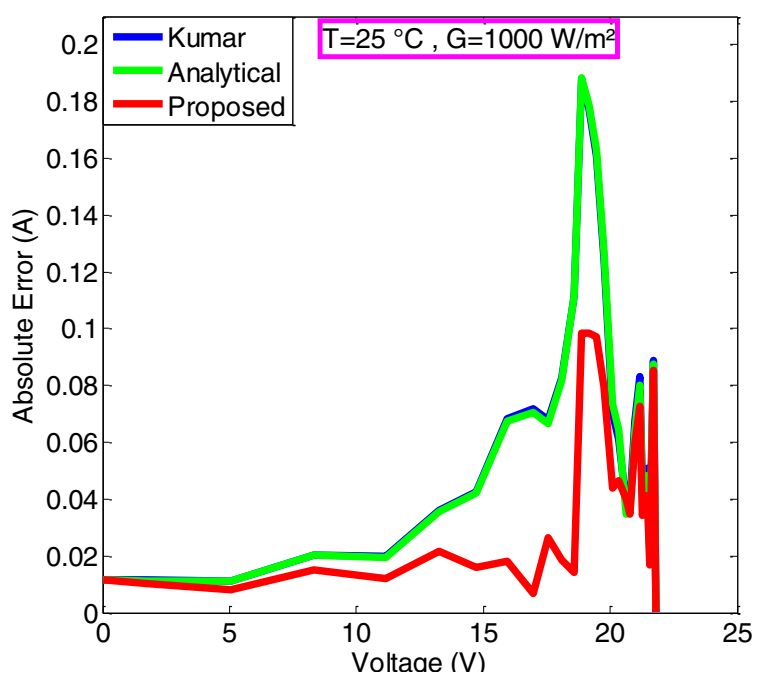

Fig. 7. Absolute errors of the three methods for the PV module Shell SQ80. 


\subsubsection{Prediction of I-V curves at non-standard test conditions}

To evaluate the accuracy of the proposed approach under non-standard test conditions (non-STC) and to predict I-V curves, it is assumed that the series resistance $R_{s}$, shunt resistance $R_{p}$ and the ideality factor $\mathrm{n}$ are independent of the irradiance level and temperature [4,5]. While the variation of the photovoltaic current $\mathrm{I}_{\mathrm{ph}}$ and the reverse saturation current $I_{s}$ are the only parameters that depend on temperature and irradiance according to the equations below $[11,12]$ :

$$
\begin{gathered}
I_{\mathrm{ph}}(G, T)=\frac{G}{G_{\mathrm{STC}}}\left(I_{\mathrm{ph}, \mathrm{STC}}+K_{\mathrm{i}}\left(T-T_{\mathrm{STC}}\right)\right) \\
I_{\mathrm{s}}(G, T)=\frac{I_{\mathrm{ph}}(G, T)-\frac{V_{\mathrm{oc}}(G, T)}{R_{\mathrm{p}}}}{\exp \left(\frac{V_{\mathrm{oc}}(G, T)}{n \mathrm{~N}_{\mathrm{s}} V_{\mathrm{th}}(T)}\right)-1}
\end{gathered}
$$

$\mathrm{I}_{\mathrm{ph}, \mathrm{STC}}, \mathrm{T}_{\mathrm{STC}}$, and $\mathrm{G}_{\mathrm{STC}}$ are respectively the photo-current, the module temperature, and the solar irradiation at standard test condition $(\mathrm{STC}) . \mathrm{K}_{\mathrm{i}}\left(\mathrm{A} /{ }^{\circ} \mathrm{C}\right)$ is the temperature coefficient of short-circuit current.

To evaluate the value of the open-circuit voltage, as a function of module temperature and solar irradiation, we introduce a new analytical expression as follow:

$$
\begin{aligned}
& V_{\mathrm{oc}}(G, T)=\left(V_{\mathrm{oc}, \mathrm{STC}}+\mathrm{K}_{\mathrm{v}}\left(T-T_{\mathrm{STC}}\right)\right) \\
& \times\left(1+\mathrm{a}\left(G-G_{\mathrm{STC}}\right)\right)\left(\frac{G}{G_{\mathrm{STC}}}\right)^{\mathrm{b}}
\end{aligned}
$$

$\mathrm{V}_{\text {oc,STC }}$ is the open-circuit voltage at STC. $\mathrm{K}_{\mathrm{v}}$ $\left(\mathrm{V} /{ }^{\circ} \mathrm{C}\right)$ is the temperature coefficient of open-circuit voltage. The coefficients $a$ and $b$ are two adjustment parameters.

The new model is compared to one of the most use model from the literature $[4,5]$ given by:

$$
\begin{aligned}
& V_{\mathrm{oc}}(G, T)=V_{\mathrm{oc}, \mathrm{STC}}+\mathrm{K}_{\mathrm{v}}\left(T-T_{\mathrm{STC}}\right) \\
& +n V_{\mathrm{th}} \ln \left(\frac{G}{G_{\mathrm{STC}}}\right)
\end{aligned}
$$

To extract the adjustment parameters a and $b$, we have used fitting of measured values of open-circuit voltage at $25^{\circ} \mathrm{C}$ and five solar irradiation values with analytical expression giving by equation (18).

Table 4 regroups the necessary specific parameters for switching to non-standard test conditions, available in the datasheet and extracted from measured I-V characteristic for the PV panel Shell SQ80. As it can be seen, the temperature coefficients are highly affected by the small error between the extracted parameters from the $\mathrm{I}-\mathrm{V}$ curve and those available in the datasheet, thing that can lead to the misprediction of the I-V and P-V characteristics for external conditions.

Table 4. The necessary specific parameters for switching to non-standard conditions available in datasheet and extracted from measured I-V characteristic for the PV panel Shell SQ80.

\begin{tabular}{|c|c|c|}
\hline Parameter & Datasheet value & $\begin{array}{c}\text { Measured } \\
\text { value }\end{array}$ \\
\hline $\mathrm{K}_{\mathrm{i}}\left(\mathrm{A} /{ }^{\circ} \mathrm{C}\right)$ & $1.4 \times 10^{-3}$ & $5.681 \times 10^{-4}$ \\
\hline $\mathrm{K}_{\mathrm{V}}\left(\mathrm{V} /{ }^{\circ} \mathrm{C}\right)$ & $-81 \times 10^{-3}$ & -0.0734 \\
\hline $\mathrm{a}$ & - & $3.22110^{-5}$ \\
\hline $\mathrm{b}$ & - & 0.02492 \\
\hline
\end{tabular}

Figure 8 shows the predicted values of the opencircuit voltage of the PV panel SQ80 using the proposed model, compared to the old model and the measured values. From this figure, it can be seen that the new model gives the best prediction of the open-circuit voltage value, especially for low levels of irradiance. On the other side, the prediction using the old model becomes worse for low irradiances thing that can also be noted from figure 9 giving the absolute errors for the two models.

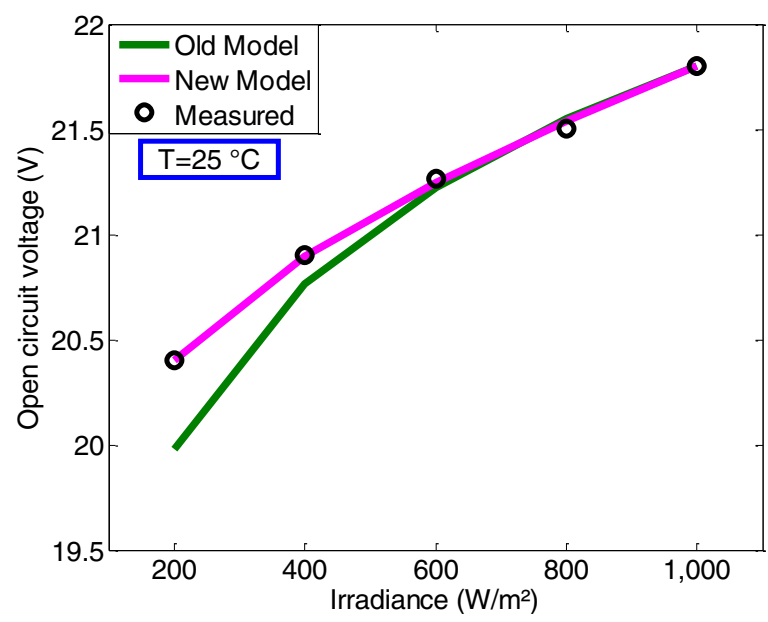

Fig. 8. Open circuit voltage obtained using the two models of the open-circuit voltage for different levels of irradiance for the PV panel shell SQ80.

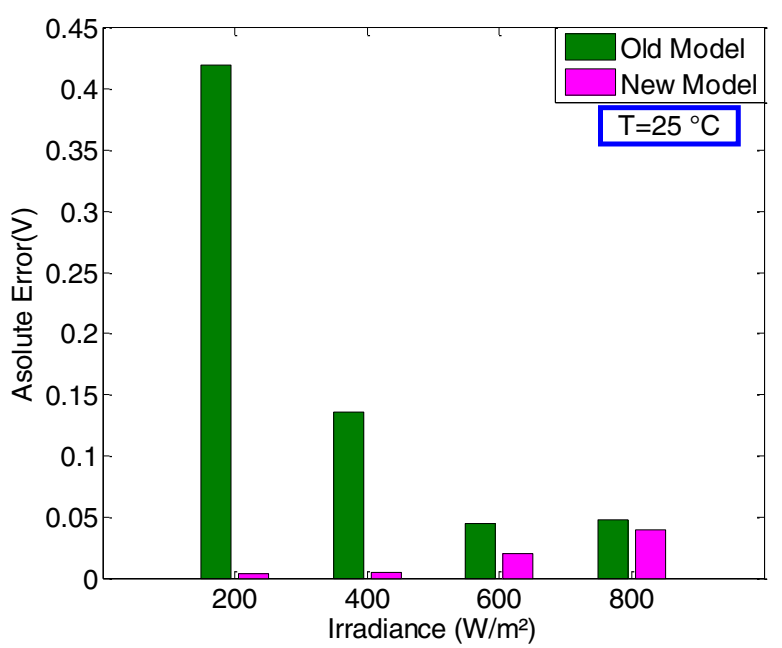

Fig. 9. The absolute error relative to the prediction of the open circuit voltage using the two models for different levels of irradiance for the PV panel shell SQ80. 
Figures 10, 11, and 12 present respectively the predicted $\mathrm{I}-\mathrm{V}$ characteristics using the current method, and the new analytical model of $\mathrm{V}_{\mathrm{oc}}$, the NRMSE variation and the absolute errors of the two models at $25^{\circ} \mathrm{C}$ and different solar irradiations. As it can be noted, the new proposed model of the open-circuit voltage for non-standard test conditions shows a good accuracy, especially for the lowest values of irradiance and the NRMSE does not exceed 3,5\%.

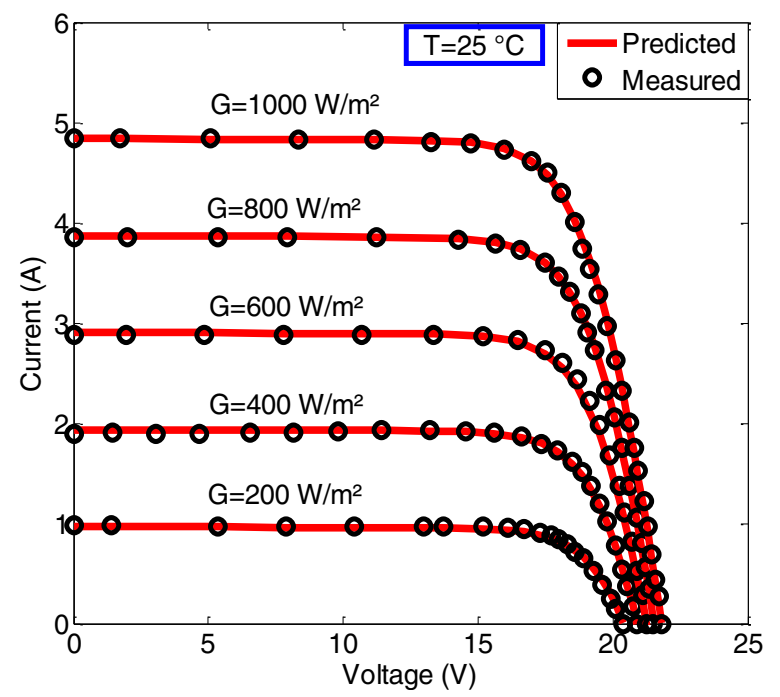

Fig. 10. Predicted I-V curves using the proposed methods and measured data at different levels of irradiance for the PV module Shell SQ80 under STC conditions.

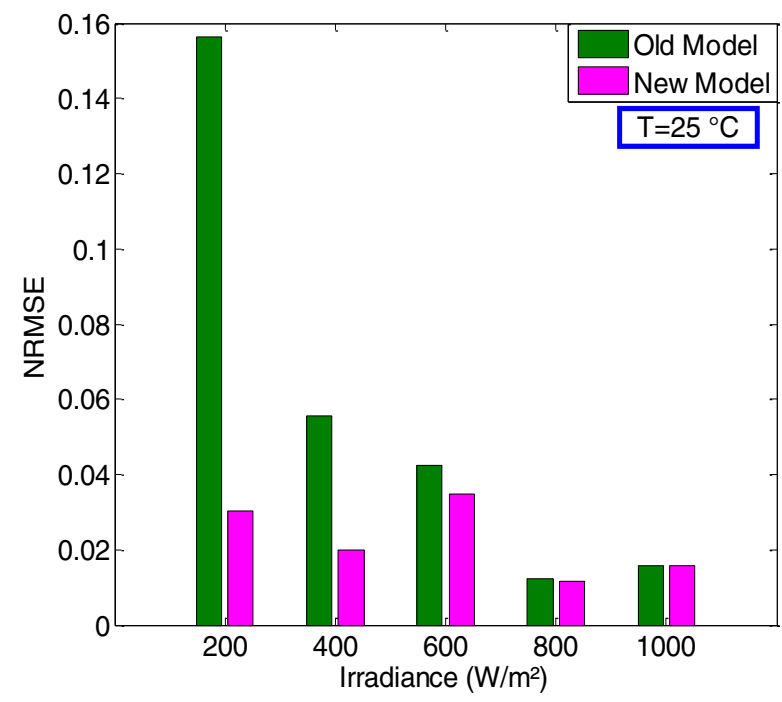

Fig. 11. Normalized root mean square error obtained using the new model and old model of the open-circuit voltage at different levels of irradiance for the PV panel shell SQ80.

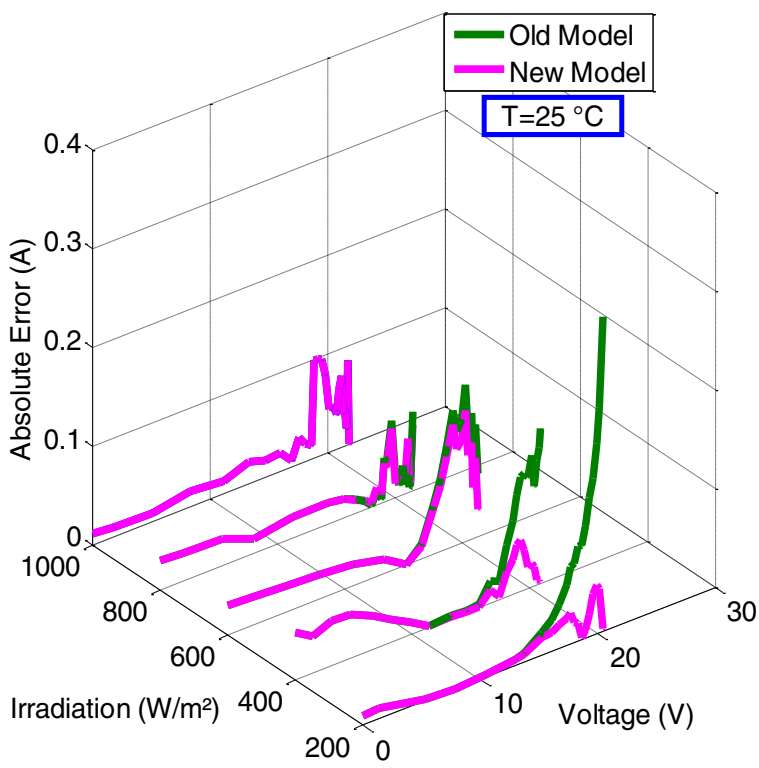

Fig. 12. Absolute errors obtained for the predicted I-V characteristics using the new model and old model for the PV panel shell SQ80 under different levels of irradiance.

Figure 13 shows the absolute errors relative to the predicted maximum power point using the new method and the new model of the open-circuit voltage, compared to the old model. It can be deduced that the new model guarantees good convergence of the theoretical maximum power point towards the measured value, with a good accuracy for all irradiation levels, even for the lowest ones, unlike the old one.

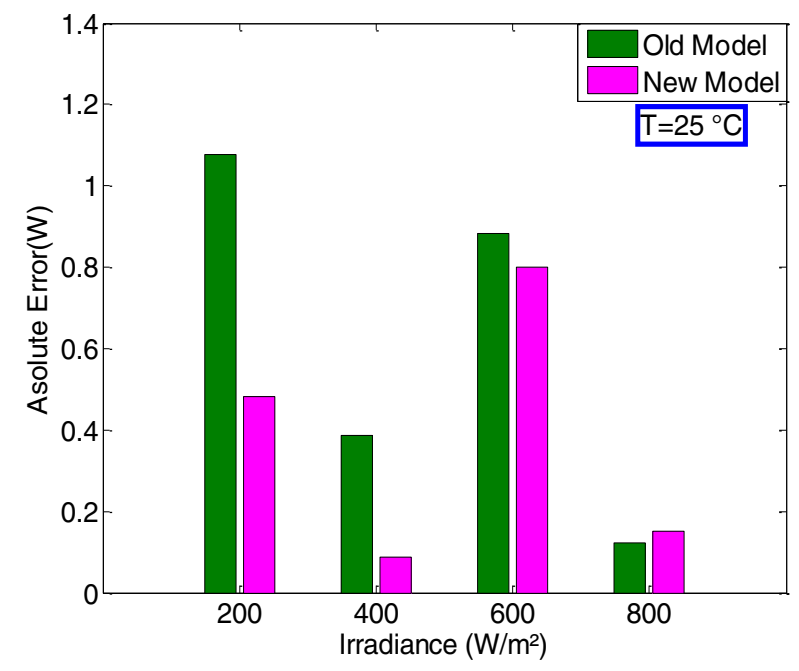

Fig. 13. Absolute errors relative to the predicted maximum power point using the two models of the open-circuit voltage for the PV panel shell SQ80 under different levels of irradiance.

Figures 14, 15, and 16 present respectively the predicted I-V characteristics using the current method, the NRMSE variation and the absolute error at 1000 $\mathrm{W} / \mathrm{m}^{2}$ and different module temperatures. The proposed method predicts the I-V curves with good accuracy and the NRMSE values does not exceed $2,6 \%$ for the temperature variation. 


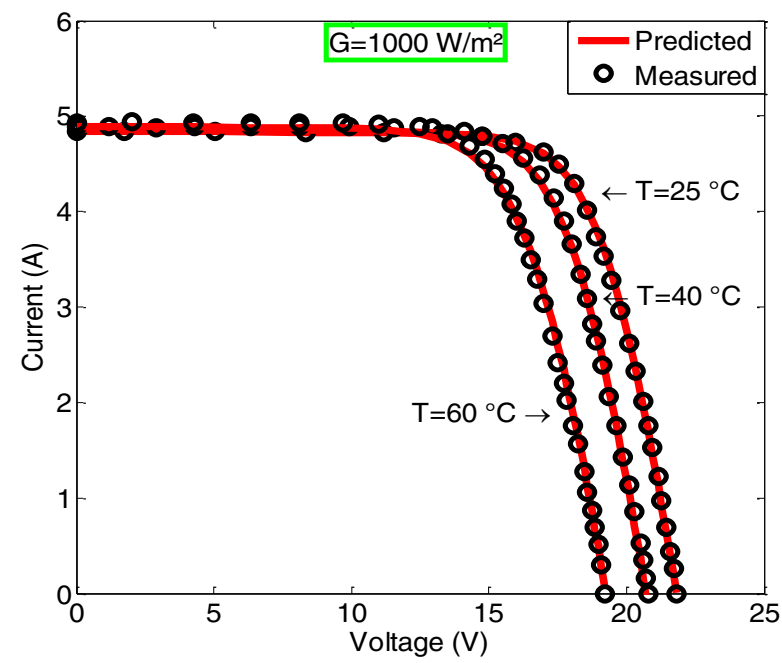

Fig. 14. Predicted I-V curves using the proposed method, and measured data at different levels of temperature for The PV module Shell SQ80.

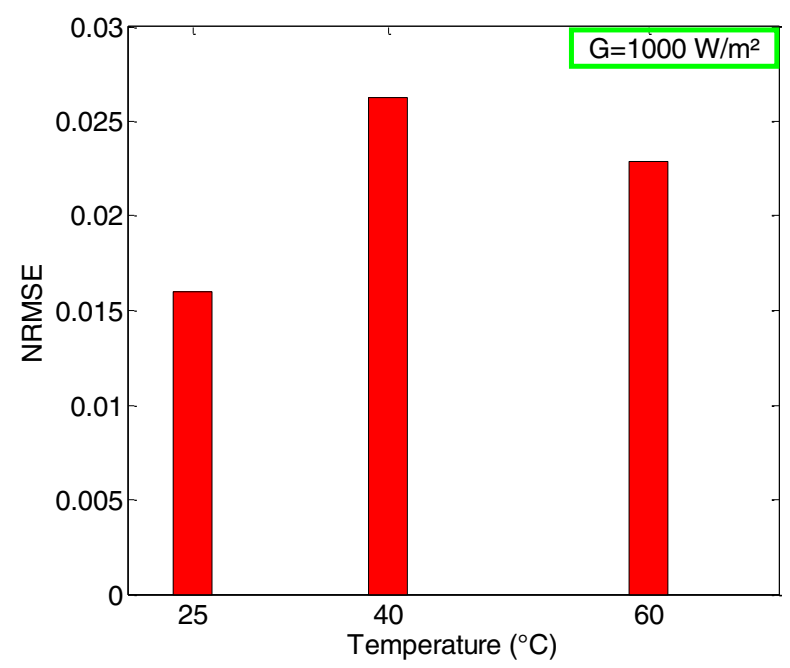

Fig. 15. Normalized root mean square error at different levels of temperature for the PV panel shell SQ80.

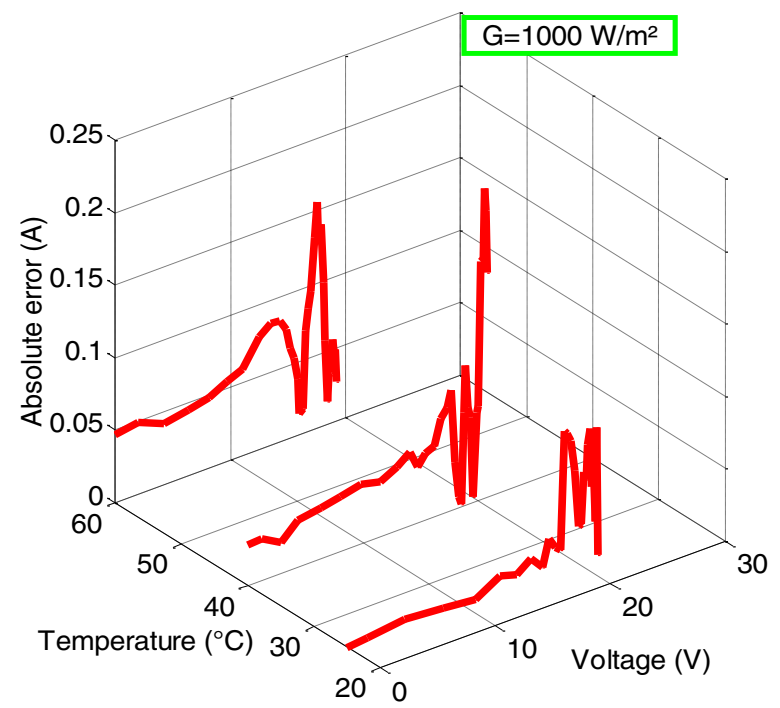

Fig. 16. Absolute errors obtained for the predicted I-V characteristics for the PV panel shell SQ80 under different levels of temperature.

\section{Conclusion}

In this work, we have introduced an accurate method to extract the values of the five parameters for the single diode model using a numerical approach. The method has been tested first for the RTC solar cell, second for the Shell SQ80 photovoltaic module. Without using any kind of approximations, the new approach showed the best accuracy compared to the other methods from the literature. The current paper proposes as well a new analytical model of open-circuit voltage to predict the $\mathrm{I}-\mathrm{V}$ and $\mathrm{P}-\mathrm{V}$ characteristics for non-standard test conditions with the best precision.

\section{References}

1. https://www.fellah-trade.com/fr/developpementdurable/energies-renouvelables-maroc.

2. M. Kumar, A. Kumar, ELSEVIER, Solar Energy, 158 (2017)

3. M.Hejri, H. Mokhtari, M. R. Azizian, L. Söder, IJ\&SE, 84 (2013)

4. I. Nassar-eddine. A. Obbadi, Y. Errami, A. El fajri, M. Agunaou, ELSEVIER, ECM 119 (2016)

5. A. Benahmida, N. Maouhoub, H.Sahsah, CS\&IT, Vol 2, N0 2 (2021)

6. A. Laudani, F.R, Fulginei, A. Salvini, Sol. Energy 103 (2014)

7. J. Ma, Z. Bi, T. O. Ting, S. Hao, W. Hao, E.C. \&. M 79 (2013)

8. A. Ortiz-Conde, F.J. García Sanchez, J. Muci, Sol. Energy Mater. Sol. Cells (3) 90 (2006)

9. A. Kapoor, V. K. Sharma, K. N. Tripath, phys. stat. sol. (a) 136 (1993)

10. Shell Solar Product Information Sheet. http://www.solarcellsales.

11. N.Maouhoub, J.C.E 17 (2018).

12. J. Bai, S. Liu, Y. Hao, Z. Zhang, M. Jiang, Y. Zhang, E.C. \&. M 79 (2013) 